\title{
SISTEM INFORMASI ALUMNI PROGRAM STUDI INFORMATIKA UNIVERSITAS TEKNOLOGI SUMBAWA BERBASIS WEB
}

\author{
Rodianto ${ }^{1)}$, Muhammad Abduh Robbani ${ }^{2)}$, Nora Dery Sofya ${ }^{3)}$ \\ ${ }^{1)}$ Dosen Teknik Informatika, Universitas Teknologi Sumbawa \\ 2), 3) Mahasiswa Teknik Informatika, Universitas Teknologi Sumbawa \\ Email: rodianto@uts.ac.id ${ }^{1}$, abduhrabbani96@gmail.com $^{2)}$, nora.dery.sofya@uts.ac.id ${ }^{3)}$
}

\begin{abstract}
Abstraksi
Dalam dunia pendidikan pemanfaatan teknologi informasi adalah hal yang wajib diterapkan salah satunya penggunaan internet yang dapat dimanfaatkan sebagai media penyebaran informasi. Program Studi Informatika Universitas Teknologi Sumbawa merupakan program studi yang sudah meluluskan banyak alumni, akan tetapi sejauh ini belum tersedianya portal yang dapat mengelola informasi terkait keberadaan para alumninya. Hal tersebut menyebabkan pihak program studi kesulitan dalam mendapatkan informasi terkini para alumninya ketika dibutuhkan. Oleh karena itu, pada penelitian ini dirancang suatu sistem informasi alumni berbasis website yang bertujuan memudahkan pihak Program Studi Informatika Universitas Teknologi Sumbawa dalam melakukan pengelolaan dan pencarian data informasi terkait alumni. Dalam membangun sistem ini peneliti menggunakan bahasa pemrograman PHP dengan Framework CodeIgniter dan MySQL sebagai databasenya. Dan untuk pengembangan perangkat lunak nya menggunakan model Waterfall. Harapannya ketika diimplementasikan sistem ini dapat digunakan oleh pihak program studi maupun alumni dalam melakukan pengelolaan informasi alumni sehingga mempermudah dan mempercepat dalam melakukan pendataan dan pelaporan data-data alumni yang ada.
\end{abstract}

Kata kunci : Sistem Informasi, Data, Alumni, Program Studi Informatika Universitas Teknologi Sumbawa, PHP

\begin{abstract}
In the world of education the utilization of information technology is something that must be implemented, one of which is the use of the internet which can be used as a medium for disseminating information. Informatic Study Program of Sumbawa University of Technology is a study program that has graduated many alumni, but so far there is no portal that can manage information regarding the whereabouts of its alumni. This causes the study program difficulties in getting the latest information of the alumni when needed. Therefore, in this research a website-based alumni information system was designed which aims to facilitate the Informatic Study Program of Sumbawa University of Technology in managing and searching for information related to alumni data. In building this system researchers used the PHP programming language with CodeIgniter Framework and MYSQL as the database. Then for the development of this software is using Waterfall model. It is hoped that when this system is implemented it can be used by study programs and alumni in managing alumni information, making it easier and faster to conduct data collection and reporting of existing alumni data.
\end{abstract}

Keywords : Information Systems, Data, Alumni, Informatic Study Program of Sumbawa University of Technology, PHP

\section{PENDAHULUAN}

Perkembangan teknologi informasi yang sangat pesat membuat segalanya menjadi mudah. Terutama sejak adanya jaringan internet, komunikasi dan penyebaran informasi menjadi lebih cepat dan mudah. Di dalam dunia pendidikan pemanfaatan teknologi informasi adalah hal yang wajib diterapkan salah satunya pemanfaatan teknologi komputer, selain sebagai media pembelajaran, bisa juga dimanfaatkan sebagai alat bantu pengolah data, dan media penyimpanan informasi.

Program Studi (Prodi) Informatika merupakan salah satu program studi yang terdapat pada Fakultas Teknik Universitas Teknologi Sumbawa. Meskipun baru beberapa tahun Prodi Informatika Universitas Teknologi Sumbawa sudah meluluskan mahasiswamahasiswa yang berkompeten namun, sejauh ini belum tersedianya portal yang dapat menghubungkan pihak program studi dan para alumni untuk saling bertukar informasi. Data alumni merupakan salah satu contoh dari suatu sistem informasi yang dapat membantu pekerjaan dari suatu instansi pendidikan baik dalam mengolah data sampai memberikan data secara lengkap lewat tersedianya layanan informasi. Saat ini, data-data alumni Prodi Informatika Universitas Teknologi Sumbawa masih belum lengkap, karena memang sistem pengisian data alumni yang masih memanfaatkan google form yang kemudian data file yang diapatkan disimpan didalam komputer, para 
alumni dan pihak program studi akan kesulitan dalam mendapatkan data informasi terbaru dari alumni itu sendiri, karena harus melakukan proses pengisian data seperti sebelumnya, dan tentunya sangat tidak efektif.

Untuk mengatasi masalah tersebut maka peneliti menawarkan suatu sistem informasi alumni yang dapat menginformasikan data secara akurat dari para alumni yang ada. Guna mendapatkan informasi yang akurat dan mudah dalam pengaksesan datanya, maka informasi dapat dirangkum dalam sebuah sistem informasi yang tentunya dapat mempermudah proses akses data tersebut pada database. Dengan adanya sistem pengelolaan data informasi alumni ini diharapkan dapat memudahkan pihak program studi maupun universitas dalam pengelolaan dan pencarian data informasi alumni yang sudah ada saat ini.

\section{TINJAUAN PUSTAKA}

\section{Tinjauan Pustaka}

Setelah melakukan observasi terhadap beberapa penelitian lainnya terkait dengan penelitian yang penulis lakukan, penulis menemukan keterkaitan dengan proses yang penulis lakukan.

Penelitian pertama dari skripsi (Yusi Ardi Bisanrso, 2012) yang berjudul "Pembangunan Sistem Informasi Berbasis Web Pada Program Studi Teknik Informatika Universitas Diponegoro" yang bertujuan untuk merancang dan membangun sebuah sistem informasi alumni berbasis website yang dapat memfasilitasi alumni dan pihak program studi Teknik Informatika Universitas Diponegoro dalam memperoleh informasi yang dibutuhkan.

Dari penelitian tersebut menghasilkan sistem informasi yang mana alumni dapat berinterkasi antar sesama alumni, kemudian pihak prodi dan alumni dapat dengan mudah memperoleh informasi seperti boidata alumni lain, informasi beasiswa, lowongan pekerjaan, serta berita terkini mengenai perkembangan program studi.

\section{Landasan Teori}

\section{Pengertian Sistem Informasi}

\section{a. Sistem}

Sistem adalah sekumpulan elemen yang saling terkait atau terpadu yang dimaksudkan untuk mencapai suatu tujuan, jika dalam sebuah sistem terdapat elemen yang tidak memberikan manfaat dalam mencapai tujuan yang sama, maka elemen tersebut dapat dipastikan bukanlah bagian dari sistem (Kadir, 2003) [1].

\section{b. Informasi}

Informasi adalah data yang telah diolah menjadi sebuah bentuk yang berarti bagi penerimanya dan bermanfaat dalam pengambilan keputusan saat ini atau saat mendatang (Kadir, 2003) [1].

Dari definisi sistem dan informasi diatas dapat disimpulkan bahwa sistem informasi adalah unsur atau komponen yang saling berhubungan untuk mengumpulkan data, mengelolah data dan menghasilkan informasi bagi pengguna. Informasi yang disampaikan kepada pengguna merupakan hasil data yang sudah diolah menjadi sebuah informasi yang lengkap dan akurat.

\section{Definisi Alumni}

Alumni merupakan orang-orang yang telah selesai atau tamat dari suatu sekolah atau perguruan tinggi. Alumni merupakan bagian yang tidak dapat dipisahkan dalam sebuah siklus pendidikan. Alumni menjadi sebuah penghubung sekolah dengan dan dunia global. Alumni juga berfungsi sebagai media yang menyampaikan visi dunia pada sekolah (Almanfaluthi dalam Reza, 2012) [3].

\section{Pengertian Penelitian Kualitatif}

Penelitian kualitatif adalah jenis penelitian yang temuan-temuannya tidak diperoleh melalui prosedur statistik atau bentuk hitungan lainnya. Yang bertujuan mengungkapkan gejala secara holistik-kontekstual melalui pengumpulan data dari latar alami dengan memanfaatkan diri peneliti sebagai instrumen kunci. Penelitian kualitatif bersifat deskriptif dan cenderung menggunakan analisis dengan pendekatan induktif. Proses dan makna berdasarkan prespektif subyek lebih ditonjolkan dalam penelitian kualitatif (Sugiarto, 2015) [4].

\section{Pengertian Data}

Data adalah kenyataan yang menggambarkan suatu kejadian nyata, data merupakan bentuk informasi yang masih mentah sehingga perlu diolah lebih lanjut agar menghasilkan keluaran yang bermanfaat. Data dapat berupa catatan-catatan dalam kertas, buku, atau tersimpan sebagai file dalam database. Data akan menjadi bahan dalam suatu proses pengolahan data. Oleh karena itu, suatu data belum dapat berbicara banyak sebelum diolah lebih lanjut (Ladjmudin, 2005) [2].

\section{Unified Modeling Language}

Unified Modeling Language (UML) adalah satu standar bahasa yang banyak digunakan didunia industri untuk mendefinisikan requirement, membuat analisis dan desain, serta menggambarkan arsitektur dalam pemrograman berorientasi objek. UML menyediakan serangkaian gambar dan diagram yang sangat baik. Beberapa diagram memfokuskan diri pada ketangguhan teori object oriented dan sebagian lagi memfokuskan pada detail rancangan dan konstruksi. Semua dimaksudkan sebagai sarana komunikasi antar tim pengembang maupun dengan pengguna (Rosa dan Shalahuddin, 2018) [5].

\section{Model Waterfall}

Model air terjun (waterfall) sering juga disebut model sekuensial linier atau alur hidup klasik. Model ini menyediakan pendekatan alur hidup perangkat lunak secara sekuensial atau terurut dimulai dari analisis, desain, pengodean, pengujian, pengembangan 
sistem informasi yang dan sekuensial (Rosa dan Shalahuddin, 2018) [5].

Dibawah ini gambar dari tahapan-tahapan dalam model waterfall:

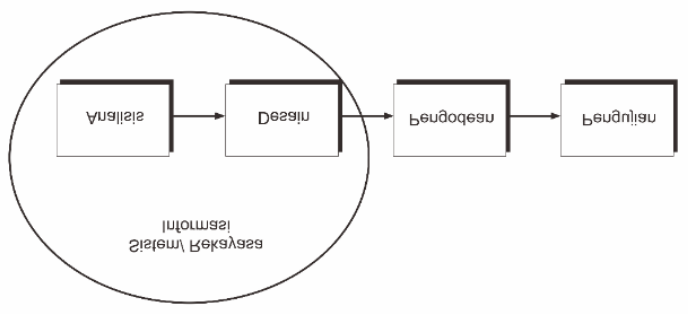

Gambar 1. Model Waterfall

\section{METODE PENELITIAN}

Tahapan yang dilakukan penulis dalam mengumpulkan data untuk membuat sistem ini dapat digambarkan pada alur penelitian sebagai berikut:

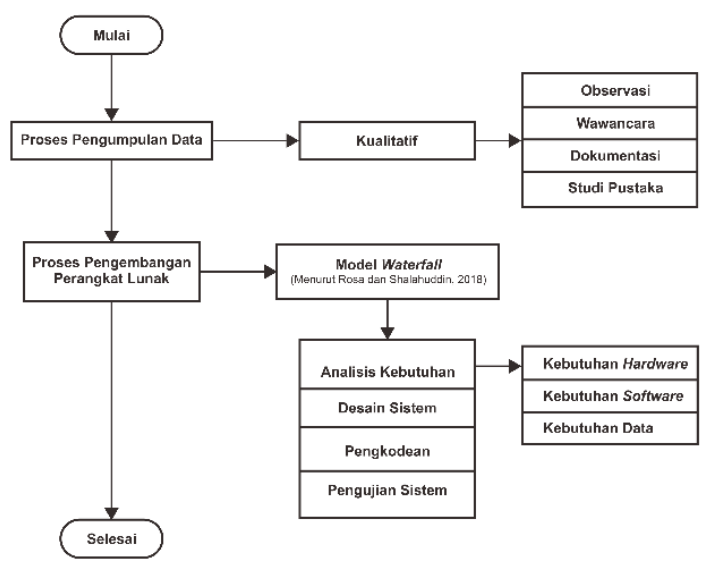

Gambar 2. Kerangka Penelitian

\section{Metode Pengumpulan Data}

Dalam melakukan penelitian ini, penulis menggunakan metode deskriptif kualitatif yang mana untuk memperoleh data yang dibutuhkan penulis melakukan beberapa cara yaitu, melakukan observasi, wawancara, dokumentasi, dan studi pustaka. Dibawah ini penjelasan selengkapnya:

\section{a. Observasi}

Pada tahap ini peneliti melakukan observasi langsung ke lokasi untuk melihat kondisi rill sistem yang ada saat ini dan mengumpulkan informasi terkait data-data alumni Program Studi Informatika. Observasi ini dilakukan untuk mencari informasi yang di perlukan dalam penelitian.

\section{b. Wawancara}

Pada tahap ini penulis melakukan pengumpulan data melalui tanya jawab dan diskusi dengan Ibu Nora Dery Sofya, S.Kom. Selaku Sekretaris Program Studi Informatika Universitas Teknologi Sumbawa.

\section{c. Dokumentasi}

Tahap dokumentasi adalah tahapan dimana peneliti mengambil data berupa dokumen maupun berkas-berkas yang terkait dengan penelitian, yaitu data-data alumni pada Program Studi Informatika Universitas Teknologi Sumbawa.

\section{d. Studi Pustaka}

Merupakan metode pengumpulan data yang diperole melalui studi kepustakaan (literature) yaitu dengan mencari bahan dari buku, internet, dan jurnal yang sesuai dengan objek yang diteliti.

\section{Metode Pengembangan Peragkat Lunak}

Metode pengembangan perangkat lunak yang penulis terapkan dalam membangun Sistem Informasi Alumni Program Studi Informatika Universitas Teknologi Sumbawa ini adalah model waterfall.

Berikut ini tahapan dalam pengembangan perangkat lunak menggunakan model waterfall:

\section{a. Analisis Kebutuhan}

Langkah ini penulis melakukan analisis terhadap sistem yang akan dibangun, kebutuhan software, kebutuhan hardware dan melakukan pengumpulan data. Proses pengumpulan data di lakukaan oleh penulis dengan melakukan observasi, wawancara, dokumentasi, dan studi pustaka. Data yang penulis kumpulkan untuk pembuatan sistem ini adalah berupa data-data dokumen alumni Program Studi Informatika Universitas Teknologi Sumbawa.

\section{b. Desain}

Dalam proses ini penulis menerjemahkan syarat kebutuhan ke sebuah perancangan software yang dapat diperkirakan sebelum dibuat coding. Yaitu penulis merancang desain sistem nya seperti flowchart, Use Case Diagram, Activity Diagram, Sequence Diagram dan Class Diagram. Kemudian juga merancang desain user interface dari Sistem Informasi Alumni Program Studi Informatika Universitas Teknologi Sumbawa.

\section{c. Pengodean}

Pada tahapan pengkodean dilakukan coding (proses membuat kode). yang mana pada tahap ini penulis mengeksekusi rancangan yang sudah dibuat sebelumnya, untuk diprogram dalam waktu kurang lebih sekitar 4 minggu, agar menghasilkan sistem yang diinginkan.

\section{d. Pengujian Sistem}

Pada proses ini peneliti akan menguji kemampuan dan keefektifan pada sistem yang telah dibuat, yang mana penulis menguji sistem yang telah jadi secara fungsional dengan metode pengujian black box. Dilakukan hal tersebut guna mengetahui kekurangan dan kelemahan pada aplikasi ini sehingga dapat dilakukan perbaikan sebelum dapat di implementasikan nantinya.

\section{HASIL DAN PEMBAHASAN}

Penerapan dari hasil metode waterfall yang telah di terapkan sampai dengan pengujian sistem pada 
penelitian ini dibagi atas pembahasan hasil perancangan dan pembangunan sistem informasi Program Studi Informatika Universitas Teknologi Sumbawa berbasis web yang telah di lakukan:

\section{Hasil Analisa Kebutuhan}

\section{a. Analisis Sistem Yang Berjalan}

Berdasarkan hasil wawancara yang telah dilakukan oleh penulis kepada Sekretaris Program Studi Informatika Universitas Teknologi Sumbawa, diketahui sistem yang sedang berjalan pada saat ini adalah:

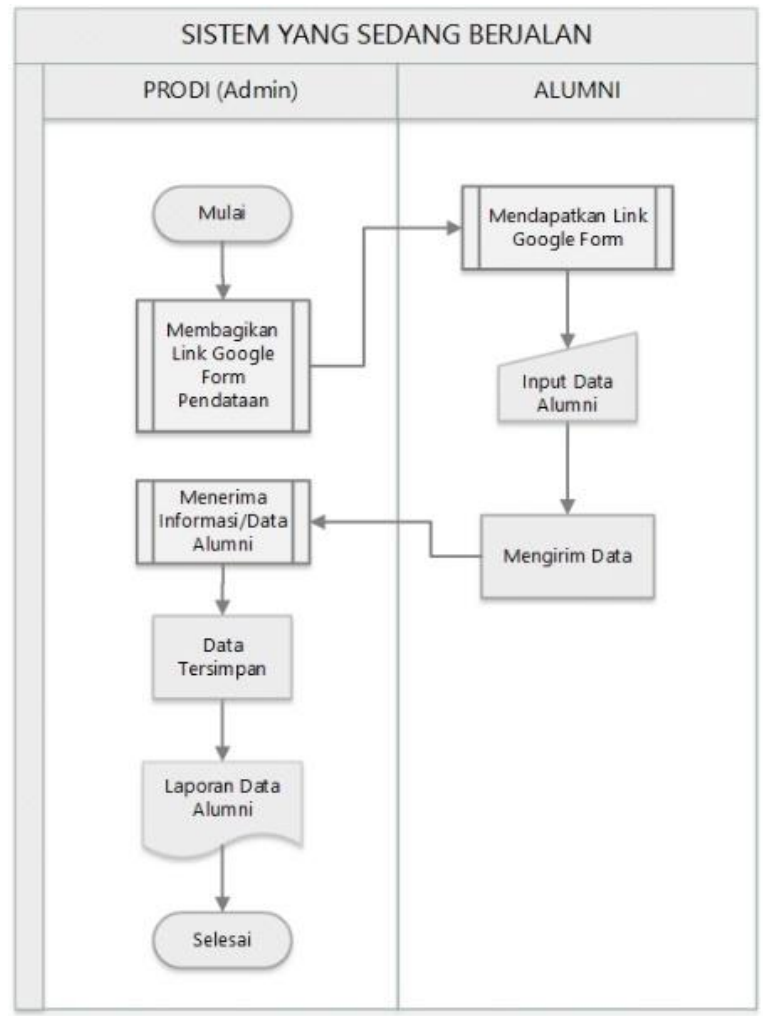

Gambar 3. Flowmap Sistem Yang Sedang Berjalan

Pada gambar Flowmap diatas menjelaskan bahwa pihak prodi yang mana dikelola oleh sekretaris prodi sebagai admin, menggunkan Google Form sebagai media untuk mengumpulkan data-data alumni. Kemudian membagikan link Google Form tersebut kepada para alumni untuk di isikan data-data para alumni tersebut. Setelah itu alumni hanya perlu mengisi data-data yang dibutuhkan dalam Google Form tersebut lalu mengirimnya kembali untuk diambil datanya oleh admin prodi. Data-data yang sudah masuk dapat disimpan dalam bentuk file Microsoft Execl dan di kelola oleh admin di dalam komputer. Dan data yang sudah tersimpan di print out untuk di jadikan laporan pihak Prodi.

\section{b. Rancangan Sistem Usulan}

Adapun rancangan sistem usulan yang akan di buat adalah sebagai berikut:

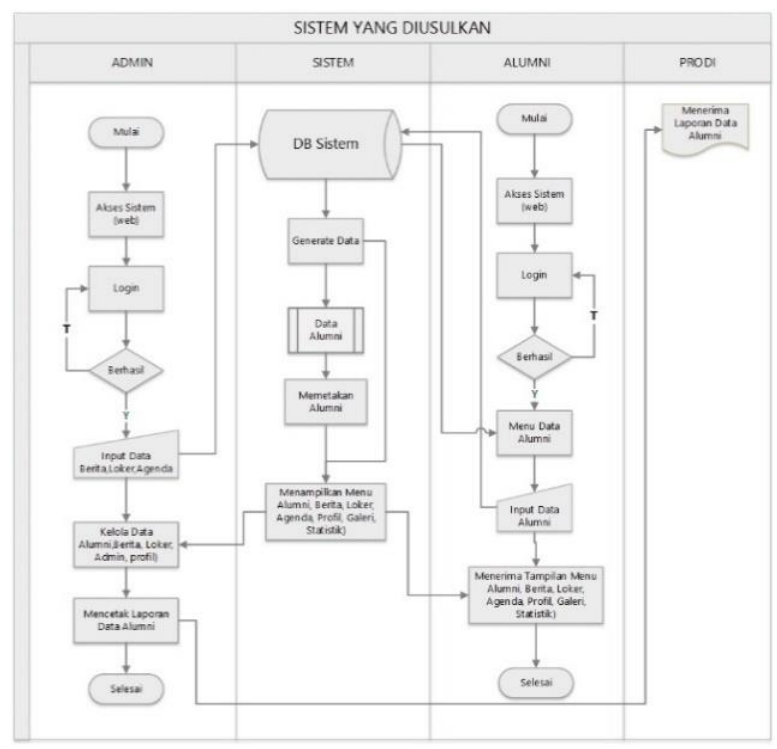

Gambar 4. Flowmap Sistem Usulan

Pada gambar Flowmap diatas menjelaskan sistem yang diusulkan oleh peneliti. Yang mana sistem ini memiliki dua hak akses yaitu user admin dan user alumni. Pada user admin yang nantinya akan di kelola admin prodi dapat mengakses sistem dan melakukan login utntuk mendapatkan akses penuh pada halaman admin. Setelah berhasil admin akan masuk kehalaman admin yang mana didalam nya admin dapat mengelola data alumni yang tersimpan dalam database setelah di input oleh user alumni. Data yang masuk sudah terpetakan oleh sistem yang mana nantinya dapat di generete laporan data alumni yang sudah dipetakan untuk diserahkan ke ketua prodi. Kemudian admin juga dapat mengelola informasi yang dibutuhkan oleh user alumni seperti informasi seluruh data alumni, lowongan kerja, berita, agenda, dan profil prodi.

Selanjutnya pada user alumni, alumni dapat melakukan login untuk dapat mengakses penuh website alumni tersebut. Setelah berhasil melakukan login alumni akan masuk ke halaman website dengan hak akses penuh sehingga alumni dapat mendaftarkan data dirinya masing-masing sebagai alumni pada menu alumni. Yang mana data-data para alumni yang terinput akan masuk kedalam database sistem dan akan otomatis dipetakan oleh sistem dengan beberpa klasifikasi. Kemudian data yang masuk akan dikelola oleh admin dan ditampilkan oleh sistem agar dapat dilihat oleh user alumni. Kemudian alumni juga dapat mengakses menu-menu yang mana setiap menu terdapat informasi mengenai alumni, seperti menu data alumni, lowongan kerja, berita, agenda, statistik dan profil prodi yang sudah dikelola oleh admin. 


\section{Perancangan Sistem}

a) Use Case Diagram

1. Use case Diagram Alumni

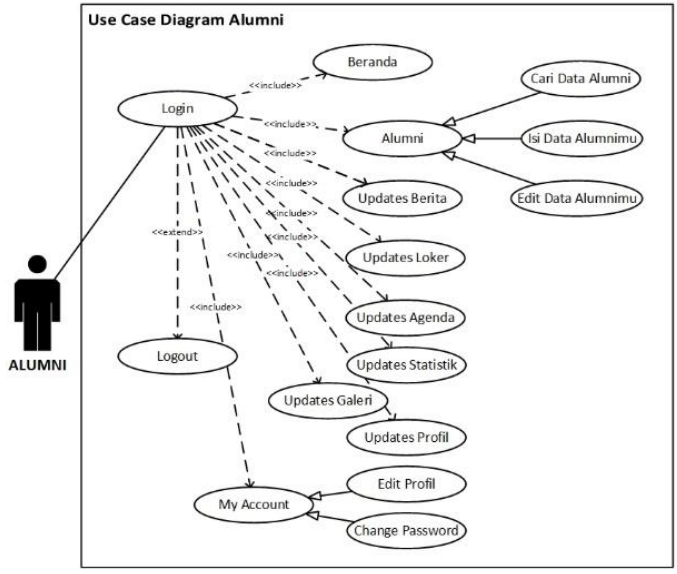

Gambar 5. Use case Diagram Alumni

Berdasarkan gambar diatas mesdiskripsikan bahwa pendaftar saat mengakses sistem dan melakukan login makan akan langsung masuk ke menu utama yang berisikan menu beranda, alumni, updates, dan my account.

2. Use case Diagram Admin

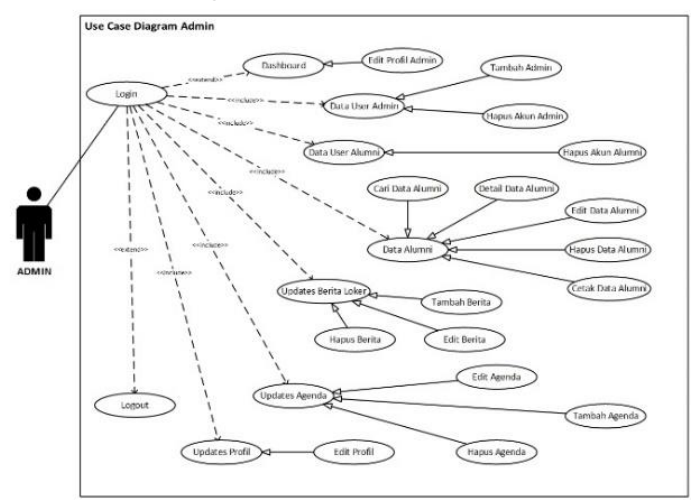

Gambar 6. Use Case Diagram Admin

Berdasarkan gambar diatas mendiskripsikan bahwa admin melakukan login terlebih dahulu agar bias mengakses menu utama halaman admin yaitu dashboard, data user admin, data user alumni, alumni, updates berita dan loker, updates agenda, updates profil, dan logout.

\section{b) Activity Diagram}

1. Activity Diagram Login Alumni

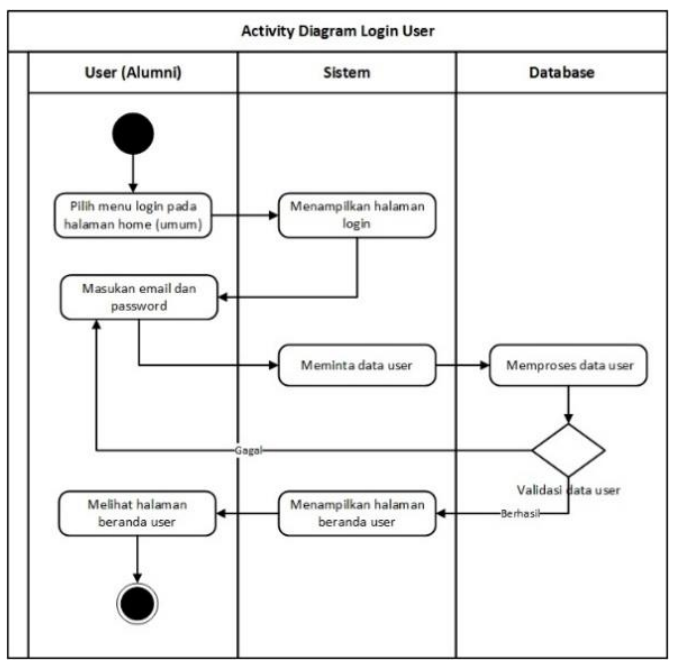

Gambar 7. Activity Diagram login Alumni

Berdasarkan gambar diatas mesdiskripsikan saat user alumni mengakses sistem dan melakukan login makan akan langsung masuk ke menu utama halaman user.

2. Activity Diagram Menu Alumni

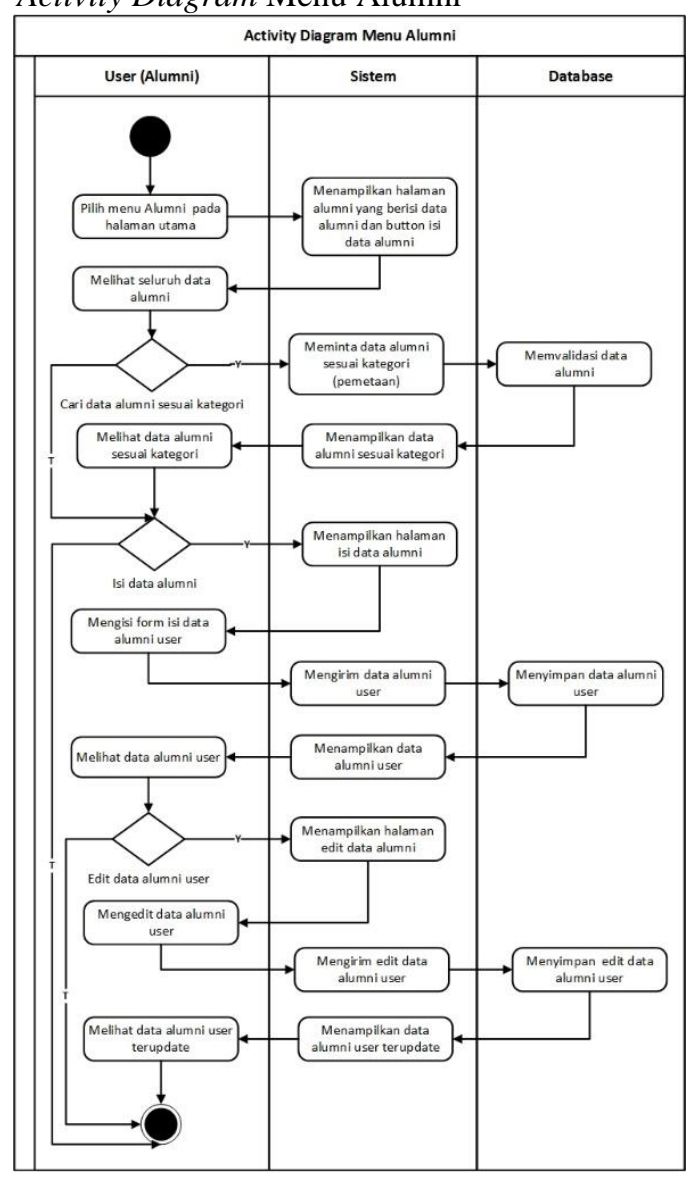

Gambar 8. Activity Diagram Menu Alumni

Berdasarkan gambar diatas mesdiskripsikan saat user alumni mengakses halaman alumni dan mengelola data identitas alumni nya seperti mengisi data alumni dan meng-uodate data alumni. 


\section{c) Sequence Diagram}

1. Sequence Diagram Login Alumni

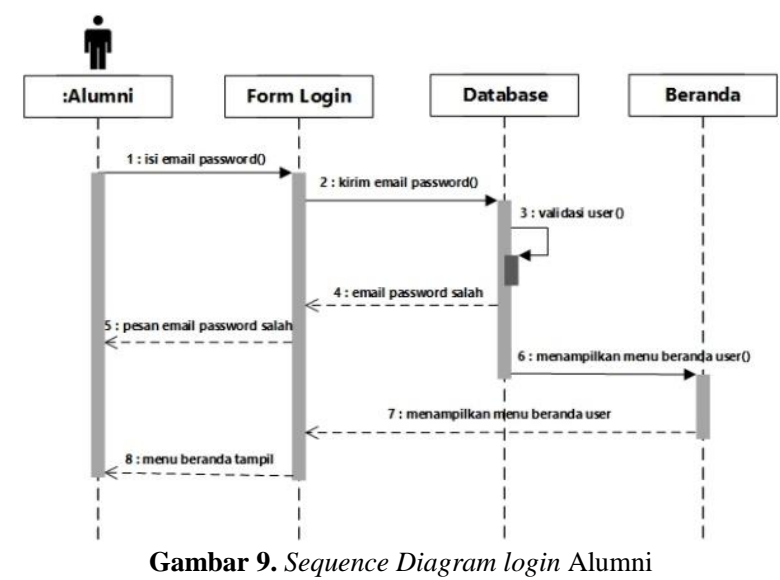

Berdasarkan gambar diatas mesdiskripsikan saat aktor alumni melakukan proses login mulai dari input data akun sampai menu halaman utama ditampilkan kepada aktor.

\section{Sequence Diagram Menu Alumni}

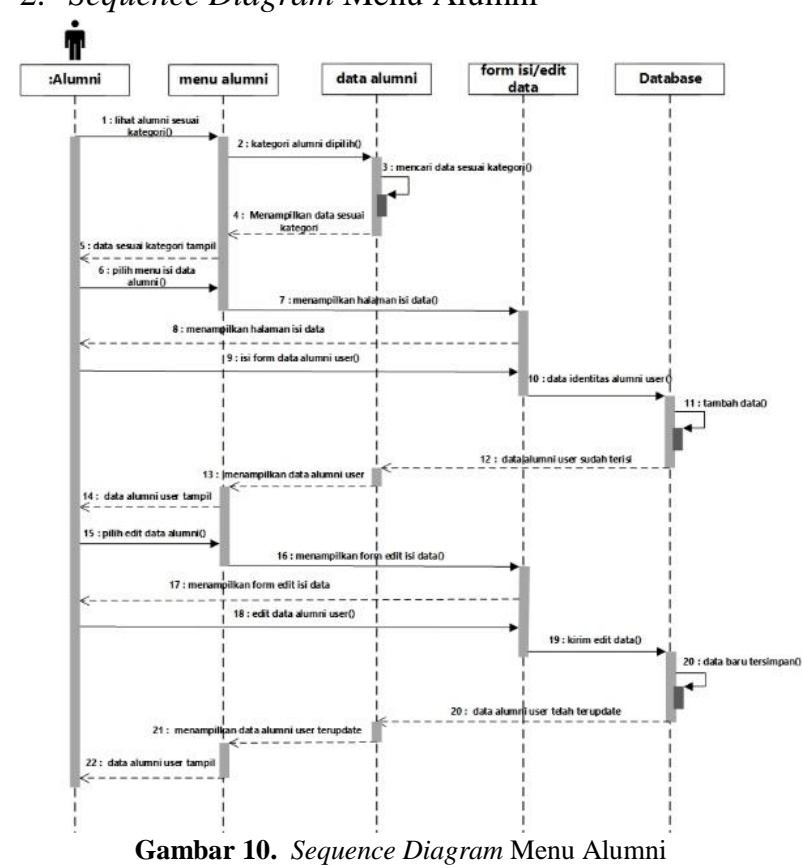

Pada gambar sequence diagram menu alumni diatas mesdiskripsikan saat aktor alumni masuk ke halaman menu alumni dan melihat data alumni serta melakukan pengelolaan data identitas alumni pribadi.

\section{d) Class Diagram}

Class diagram pada sistem ini menunjukan interaksi antar kelas dan sistem serta garis yang dihubungkan antar kelas menunjukan hubungan komunikasi antara class diagram. Berikut dibawah ini merupakan class diagram pada rancang bangun sistem informasi alumni Prodi Informatika UTS:

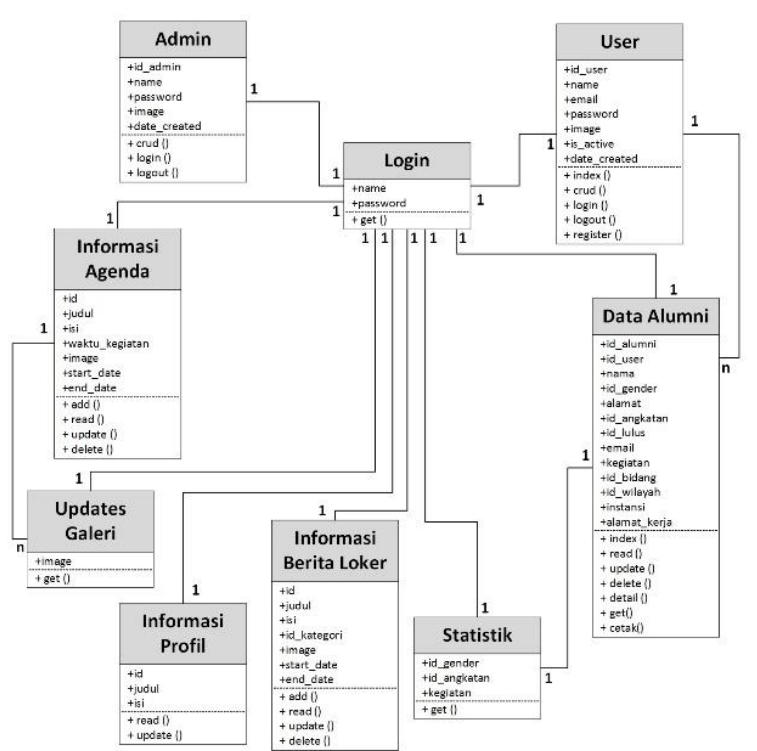

Gambar 11. Class Diagram

\section{Rancangan Database}

\section{a. Relasi Antar Tabel}

Relasi antar tabel adalah hubungan sebuah tabel dengan tabel lainnya. Sehingga tabel tidak berdiri sendiri, melainkan dapat dihubungkan antara satu dengan yang lainnya dan menjadi satu kesatuan.

Adapun Relasi Antar Tabel pada sistem informasi alumni Prodi Informatika UTS ini adalah sebagai berikut:

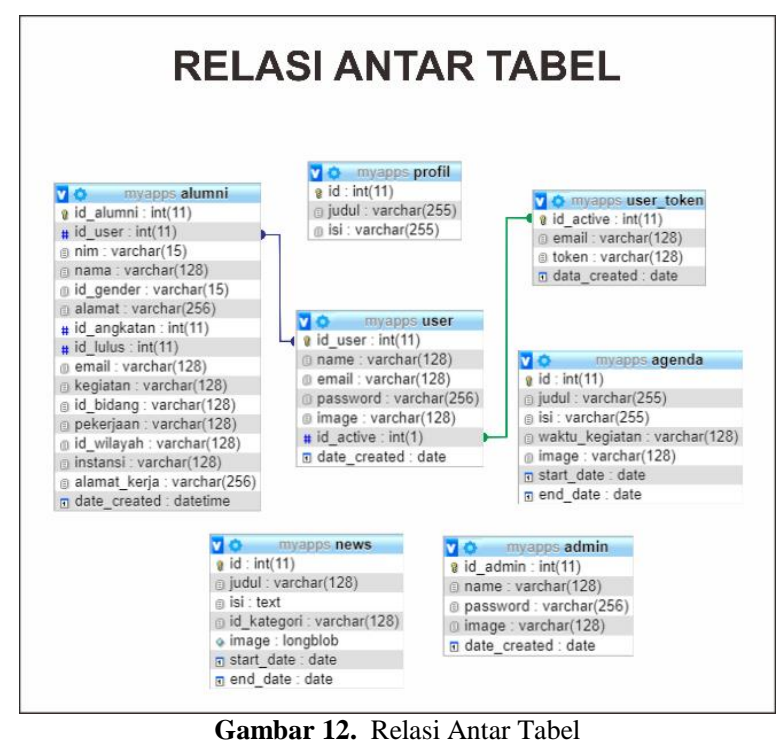

\section{Rancangan Desain Antar Muka}

Adapun rancangan tampilan yaitu terdiri dari dua bagian yaitu rancangan halaman pada admin dan rancangan halaman pada alumni, dibawah ini dijelaskan beberapa bagian diantara, rancangan tampilan halaman utama, tampilan login alumni, halaman beranda pada user alumni, halaman dashboard admin, dan halaman menu alumni pada admin: 


\section{a. Rancangan Tampilan Halaman Utama}

Berikut merupakan tampilan halaman umum pada user:

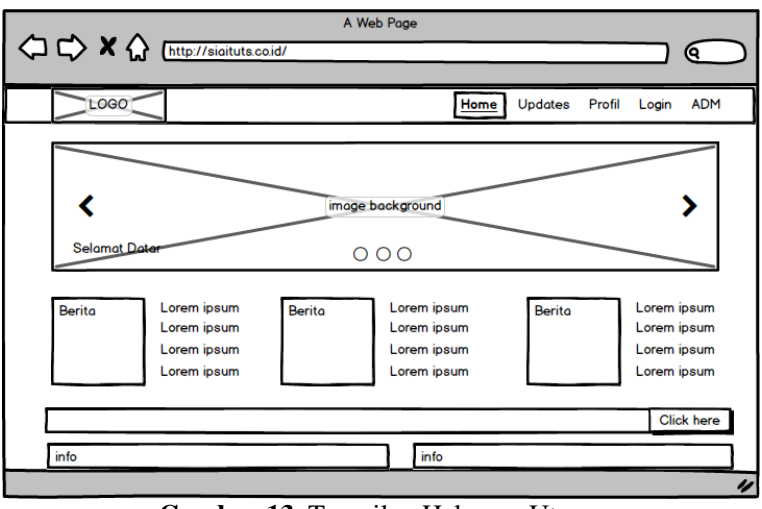

Gambar 13. Tampilan Halaman Utama

Rancangan halaman utama diatas memiliki beberapa bagian, yang pertama pada bagian header terdapat image logo dan link text menu Home, Updates, Profil, Login, dan ADM. Selanjut nya pada bagian isi halaman terdapat carousel image slideshow pada bagian atas dan baris selanjut nya terdapat block list image dan paragraf untuk menampilkan data foto dan isi berita, agenda dan lowongan kerja ter-update. Dan pada baris selanjut nya terdapat label dan paragaraf untuk menampilkna informasi lainnya.

\section{b. Rancangan Tampilan Halaman Login Alumni}

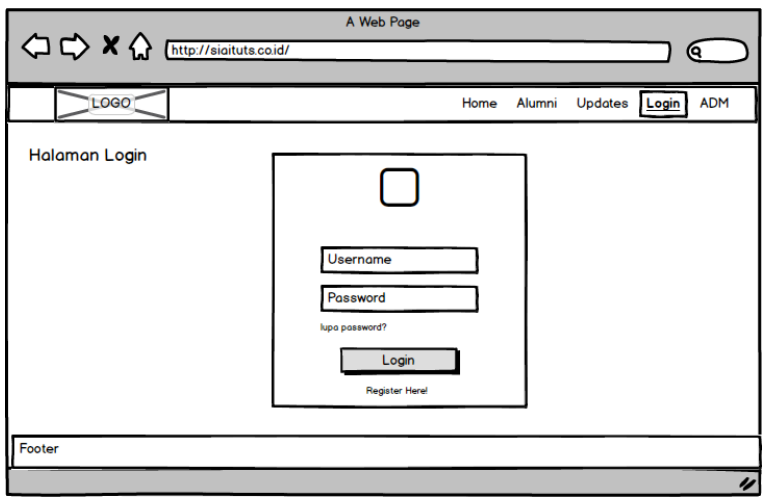

Gambar 14. Rancangan Tampilan Login Alumni

Pada rancangan halaman Menu Login diatas tedapat card form login yang didalamnya terdapat icon login user, kemudian dua field input untuk memasukan username dan password dan satu button untuk proses login. kemudian ada dua text link untuk melakukan register dan juga melakukan perbaikan password.

\section{c. Rancangan Tampilan Halaman Isi Data Alumni}

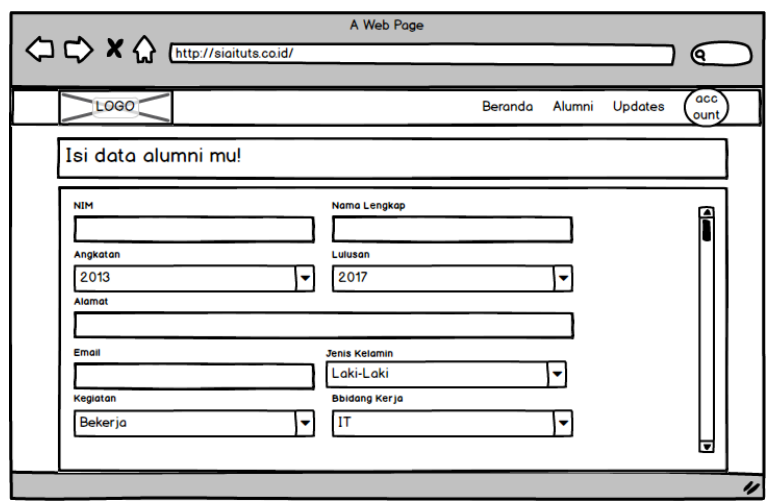

Gambar 15. Rancangan Tampilan Isi Data Alumni

Rancangan halaman isi data alumni diatas memiliki form input, dan input select identitas alumni, yaitu input NIM, Nama, Alamat, Email, Pekerjaan, Instansi, dan Alamat Instansi, dan input select Angkatan, Tahun Lulusan, Jenis Kelamin, Bidang Kerjaan, dan Wilayah Kerja. Kemuidan terdapat satu button untuk proses tambah data alumni.

\section{d. Rancangan Tampilan Dashboard Admin}

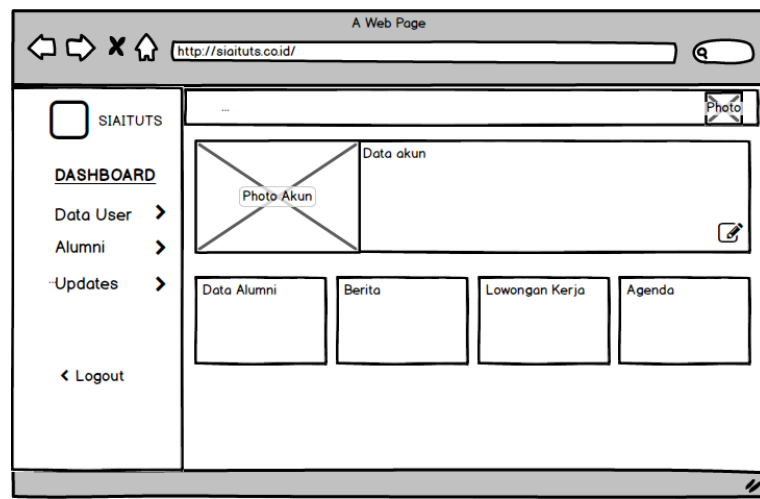

Gambar 16. Rancangan Tampilan Dashboard Admin

Rancangan halaman menu dashboard diatas adalah halaman yang pertama kali dilihat oleh admin ketika berhasil melakukan login. Terdapat beberapa bagian pada halaman dashboard admin ini, bagian pertama yaitu bagian sidebar yang mana didalam nya terdapat dashboard icon dan beberapa menu text link diantaranya menu Dashboard, Data User, Alumni, Updates, dan Logout. Selanjut nya pada bagian header terdapat image profile account, dan bagian terkahir yaitu isi dari halaman dashboard admin yaitu terdapat image view dan text paragraf data admin yang mana juga terdapat icon link edit untuk mengubah profil akun admin. Kemudian di baris selanjut nya terdapat list row data informasi data alumni, berita, lowongan kerja, dan agenda yang telah di kelola oleh admin. 
e. Rancangan Tampilan Menu Alumni Pada Admin

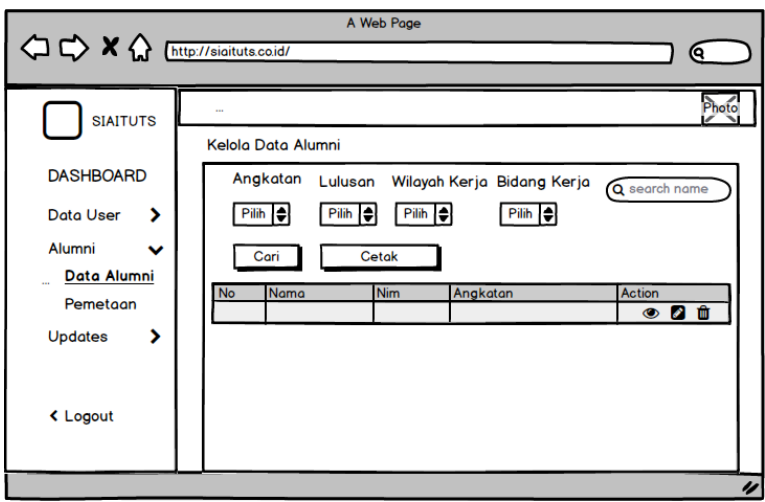

Gambar 17. Rancangan Tampilan Menu Alumni Pada Admin

Rancangan isi dari halaman menu Data Alumni diatas terdapat tabel yang menampilkan data-data informasi menegenai identitas alumni. yang mana pada tabel aksi terdapat icon untuk melihat detail, memperbaharui, dan menghapus data alumni. Kemudian diatas tabel terdapat empat input select Angkatan, Lulusan, Wilayah, dan Bidang, lalu dua button proses cari dan cetak dan kemudian satu input search.

\section{Implementasi Program} mengimplementasikannya kedalam sebuah kode yang dapat menghasilkan tamppilan sesuai rancangan yang di inginkan Adapun tampilan dari aplikasi ini adalah sebagai berikut:

\section{a. Implementasi Tampilan Halaman Utama}

Berikut merupakan tampilan halaman utama pada user:

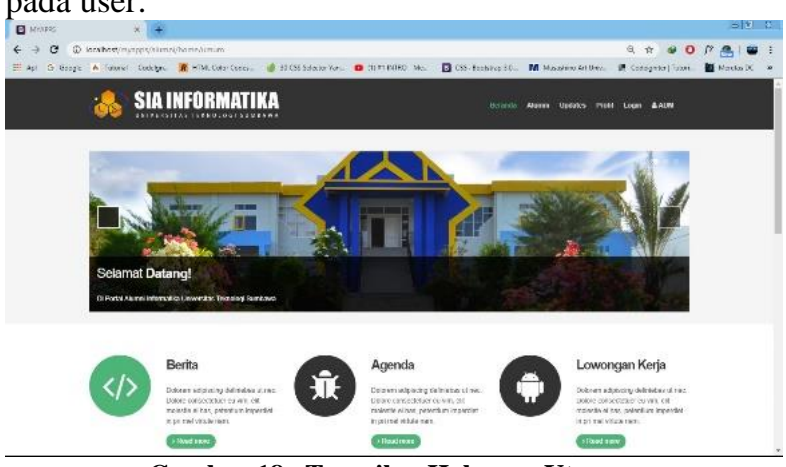

Gambar 18. Tampilan Halaman Utama

Tampilan halaman utama adalah halaman yang pertama kali dilihat oleh user saat mengakses sistem ini. Terdapat beberapa menu yaitu Menu Home, Menu Alumni, Menu Updates, dan Menu untuk admin dan alumni melakukan login. b. Implementasi Tampilan Halaman Login Alumni

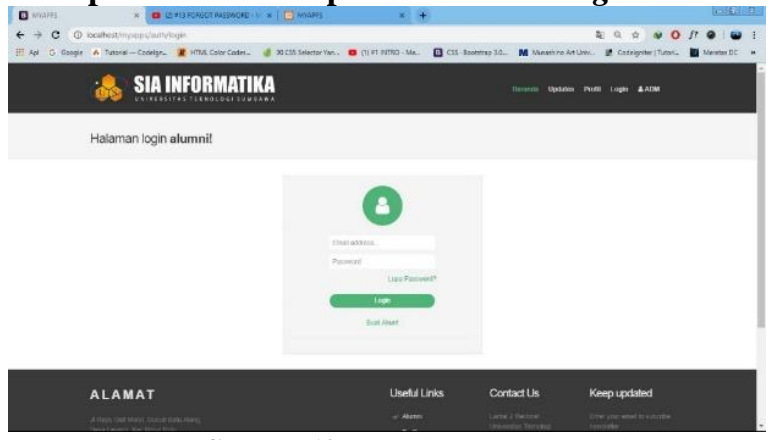

Gambar 19. Tampilan Login Alumni

Pada tampilan halaman Menu Login diatas admin atau alumni diminta memasukan username dan password untuk melakukan login. Apabila proses tersebut berhasil, maka akan muncul tampilan halaman utama tampilan utama dari masing-masing user. Jika belum memiliki akun user dapat melakukan registrasi dengan menekan link registrasi yang tedapat diabwah button login.

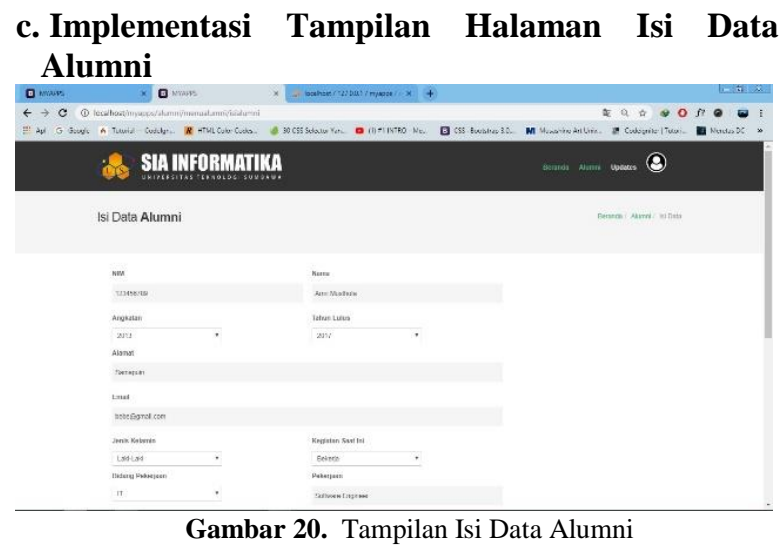

Pada tampilan halaman ini, user alumni dapat mengisi identitas alumni sesuai dengan field-field yang tersedia. Setelah mengisi, data yang masuk akan ditampilkan kembali ke halaman pada menu alumni.

\section{d. Implementasi Tampilan Dashboard Admin}

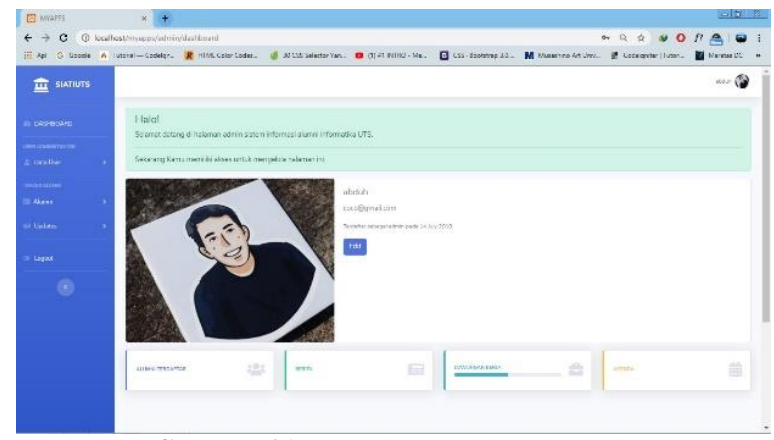

Gambar 21. Tampilan Dashboard Admin

Halaman Dashboard ini adalah halaman yang pertama kali dilihat oleh admin ketika berhasil 
melakukan login. yang mana admin dapat melihat jumlah tiap-tiap informasi yang telah dikelola.

\section{e. Implementasi Tampilan Menu Alumni Pada Admin}

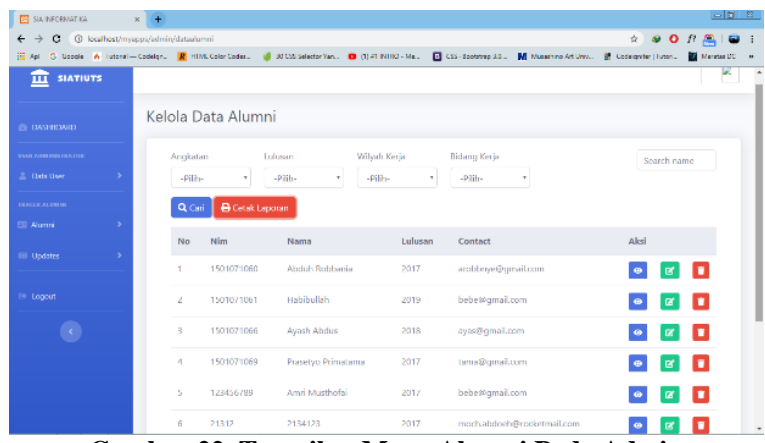

Gambar 22. Tampilan Menu Alumni Pada Admin

Halaman menu alumni pada admin ini menampilkan tabel data-data lengkap alumni yang sudah mengisi identitas. Admin dapat melihat data identitas alumni sesuai kategori yang ditentukan, kemudian admin juga dapat mengelola data-data alumni yang ada seperti melihat detail, mengubah, menghapus data, dan juga dapat mencetak data yang ada untuk dijadikan laporan.

\section{Pengujian Sistem}

Adapun hasil pengujian perangkat lunak yang dilakukan menggunakan pengujian black box testing dalam Rancang Bangun Sistem Informasi Alumni Prodi Informatika UTS adalah sebagai berikut :

\section{a. Pengujian User Alumni}

Pengujian perangkat lunak pada user alumni yang dilakukan guna mengetahui fungsi yang telah dibuat, berhasil atau tidak untuk di fungsikan.

\section{Tabel 1. Pengujian User Alumni}

\begin{tabular}{|c|c|c|c|}
\hline \multicolumn{4}{|c|}{ Kasus dan Hasil Data Uji } \\
\hline Alssi Actor & Yang Diharapkan & Pengamatan & Kesimpulan \\
\hline $\begin{array}{l}\text { Melakulkan akses } \\
\text { sistem pada local } \\
\text { server melalui } \\
\text { browser chrome } \\
\text { dengan memasukan } \\
\text { url } \\
\text { http://localhost/myo } \\
\text { pos/ }\end{array}$ & $\begin{array}{l}\text { Menampilkan } \\
\text { halam utama } \\
\text { sistem informasi } \\
\text { alumni } \\
\text { Informatika UTS }\end{array}$ & \& sia waronuarixa & Sesuai \\
\hline $\begin{array}{l}\text { Melakukan login } \\
\text { dengan meng-input } \\
\text { email dan password }\end{array}$ & $\begin{array}{l}\text { Menampilkan } \\
\text { halamann dengan } \\
\text { username sesuai } \\
\text { dengan validasi } \\
\text { email dan } \\
\text { password yang di } \\
\text { input }\end{array}$ & Halo Robbanll & Sesuai \\
\hline $\begin{array}{l}\text { Melakukan register } \\
\text { dengan meng-ivput } \\
\text { username, email, dan } \\
\text { password }\end{array}$ & $\begin{array}{l}\text { Menampilkan } \\
\text { pesan berhasil } \\
\text { melakukan } \\
\text { registrasi akun }\end{array}$ & - & Sesuai \\
\hline $\begin{array}{l}\text { Mengisi data } \\
\text { identitas alumni } \\
\text { dengan meng-input } \\
\text { data sesuai form } \\
\text { yang tersedia. }\end{array}$ & $\begin{array}{l}\text { Menampilkan data } \\
\text { identitas alumni } \\
\text { yang gudah di } \\
\text { ingut }\end{array}$ & 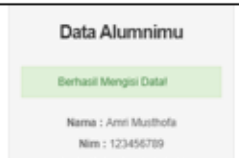 & Sesuai \\
\hline $\begin{array}{l}\text { Keluar dari halaman } \\
\text { user alumni }\end{array}$ & $\begin{array}{l}\text { Menampilkan } \\
\text { pesan anda } \\
\text { berhasil keluar }\end{array}$ & monsm & Sesuai \\
\hline
\end{tabular}

\section{b. Pengujian User Admin}

Pengujian perangkat lunak pada user admin yang dilakukan guna mengetahui fungsi yang telah dibuat, berhasil atau tidak untuk di fungsikan.

Tabel 2. Pengujian User Admin 


\begin{tabular}{|c|c|c|c|}
\hline \multicolumn{4}{|c|}{ Kasus dan Hasil Data Uji } \\
\hline Aksi Actor & Yaug Diharapkau & Pengamatal & Kesimpulan \\
\hline 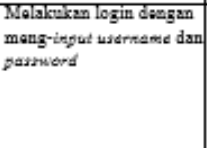 & 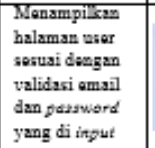 & Hede & Sostusi \\
\hline 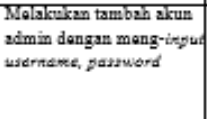 & 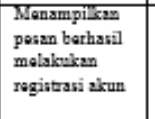 & 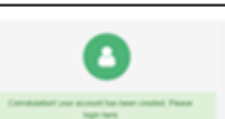 & So:usi \\
\hline 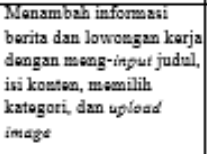 & \begin{tabular}{|l|} 
Mansmpilisam \\
pesan berhasil \\
manambeh borita
\end{tabular} & Bentual Neseroun beedx & So:usi \\
\hline 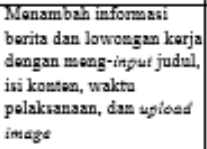 & 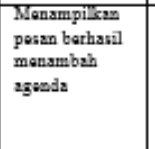 & 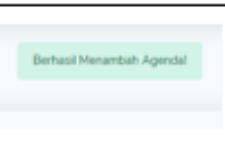 & So:usi \\
\hline 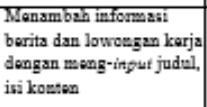 & $\begin{array}{l}\text { Mensmpisism } \\
\text { pesm torthasil } \\
\text { mongisi profil }\end{array}$ & 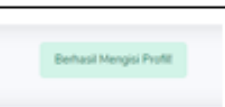 & Sostusi \\
\hline $\begin{array}{l}\text { Molakcukn cotis data } \\
\text { vlumni }\end{array}$ & $\begin{array}{l}\text { Mensmpilisam } \\
\text { tampilan paff }\end{array}$ & 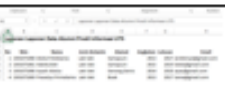 & Sortusi \\
\hline $\begin{array}{l}\text { Koluar dari halsmen usat } \\
\text { admin }\end{array}$ & 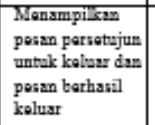 & ש & So:tuii \\
\hline & & & \\
\hline
\end{tabular}

\section{KESIMPULAN DAN SARAN}

\section{Kesimpulan}

Dari hasil analisis dan perancangan yang telah dilakukan sebelumnya, Sistem Informasi Alumni Program Studi Informatika Universitas Teknologi Sumbawa berbasis web ini telah selesai dibangun menggunakan bahasa pemrograman PHP dengan framework Codeigniter dan Database MySql dan telah diuji secara fungsional bahwa sistem dapat digunakan untuk mengelola data alumni diantaranya, mampu menyimpan data-data identitas alumni, memetakan data alumni, mencetak data alumni, dan mengelola informasi seputar alumni. Yang mana harapannya ketika diimplementasikan sistem ini dapat digunakan oleh pihak program studi maupun alumni dalam melakukan pengelolaan data alumni, sehingga mempermudah dan mempercepat dalam melakukan pendataan dan pelaporan data-data alumni yang ada.

\section{Saran}

Dari hasil rancang bangun Sistem Informasi Alumni Program Studi Informatika Universitas Teknologi Sumbawa berbasis web, penulis memberikan saran agar pada tahap selanjutnya dilakukan pengembangan, diantara nya meliputi:

1. Dalam penggunaan database untuk kedepannya menggunakan DBMS dimana penyimpanan data alumni lebih besar.
2. Menambahkan kuisioner tracer study pada sistem untuk alumni yang terdaftar.

3. Menambahkan fitur roomchat agar user alumni memiliki forum umum untuk tetap berkomunikasi dengan alumni lainnya.

4. Menambahkan fitur notifikasi yang dapat memudahkan alumni dalam mendapatkan informasi terkait berita, dan agenda ter-update dari sistem ini.

\section{DAFTAR PUSTAKA}

[1] Kadir, A. 2003. Pengenalan Sistem Informasi. Yogyakarta: Andi Offset.

[2] Ladjmudin, A. B. 2005. Desain Informasi. Jakarta: Erlangga.

[3] Reza, S. 2012. Pengembangan Sistem Informasi Alumni Brbasis Web (Studi Kasus STMIK Pringsewu). KMSI Konferensi Mahasiswa Sistem Informai Vol.1 No.1 pISSN.2337-3032.

[4] Sugiarto, E. 2105. Menyusun Proposal Penelitian Kualitatif Skripsi dan Tesis. Yogyakarta: Suaka Media.

[5] Rosa, A., \& Shalahuddin, M. 2018. Rekayasa Perangkat Lunak Terstruktur dan Berorientasi Objek (Edisi Revisi). Bandung: Informatika Bandung. 